\title{
Accuracy of Death Certificates for Recording Parkinsonian Syndromes and Associated Dementia
}

\author{
Hanxu Shi MPH ${ }^{a}$, Carl Counsell MD ${ }^{a,}{ }^{*}$ \\ a Institute of Applied Health Sciences, School of Medicine, Medical Sciences and Nutrition, Polwarth \\ Building, Foresterhill, University of Aberdeen, AB25 2ZD, United Kingdom
}

\begin{abstract}
Introduction: Death certification is often used to identify patients with certain diseases in epidemiologic research. There have been few studies looking at the accuracy of recording of parkinsonian diagnoses, any associated dementia and the cause of death on death certificates in people with parkinsonian conditions. This study aimed to assess this.

Methods: Data for these analyses were derived from a prospective incident cohort of degenerative/vascular parkinsonian syndromes with lifelong follow-up from Scotland, UK (the PINE study). In those who died, the available research and clinical care records were reviewed to establish the cause for each patient's death. The sensitivity of death certificates was calculated to detect any parkinsonian diagnosis mentioned on the death certificate, the correct specific diagnosis and the presence of dementia. The causes of death were compared between clinical records and death certificates.
\end{abstract}

Results: 277 patients had died (180 men), mean age at diagnosis and death 76.9 years and 81.9 years respectively. $66.8 \%$ of death certificates mentioned any parkinsonian syndrome but only $49.5 \%$ had the correct diagnosis. Sensitivity was highest for Parkinson's disease, those who had parkinsonian-related deaths, had longer disease durations and died out of hospital. Death certificates detected $51.2 \%$ of those with dementia. The commonest causes of death were pneumonia, end-stage parkinsonism and vascular disease with moderate agreement between case-note review and death certification.

Conclusion: Deaths certificates often do not mention underlying parkinsonism or associated dementia and so epidemiological studies should not rely on this as a sole method of identifying cases or studying mortality.

Keywords: Parkinsonian disorders; death certificates; accuracy; sensitivity; dementia 
Abstract word count: 249

Manuscript word count: 2544 


\section{Introduction}

Parkinsonism is a clinical syndrome characterised by slowness of movement, stiffness and tremor [1]. It is caused by a number of neurodegenerative diseases, most commonly Parkinson's disease, but also atypical parkinsonian disorders such as Progressive Supranuclear Palsy, Multiple System Atrophy, Corticobasal Degeneration, Dementia with Lewy Bodies and vascular parkinsonism. Patients with parkinsonism have increased mortality and reduced life expectancy [2, 3]. Dementia is a common complication of many of these diseases and contributes to mortality significantly [4].

Death certificates provide routinely available data on the direct causes of death and any contributory factors. This gives an indication of the disease specific mortality (which is sometimes used as a proxy for disease incidence over time), but they are also used in epidemiology research as a cost-effective way to identify and obtain survival data on disease cases in large cohorts, both retrospectively and prospectively. If accurate, information associated with neurodegenerative disorders on death certificates could be used to explore disease burden and course, identify causes of death, evaluate the longterm interventions and recognise priorities for clinical research and health service planning [3]. However, the utility of death certificate data for studying the epidemiology of parkinsonism may be limited due to inconsistent and inaccurate recording of parkinsonism and the causes of death on death certificates [3].

It is therefore necessary to understand the accuracy of the recording of the parkinsonian diagnosis on death certificates and the classification for the cause of death in parkinsonian patients. Few studies have looked at this but there is some evidence that a parkinsonian diagnoses and any associated dementia data are frequently omitted from the death certificates [5-7].

The main objectives of this study were to use an incident cohort of parkinsonian patients to assess: (i) how many patients who died had any or the correct parkinsonian syndrome recorded on their death certificate (i.e. the sensitivity of death certificates to 
detect parkinsonian cases if used in cohort studies) ; (ii) factors that may influence the sensitivity; (iii) how many patients who died with dementia as part of their parkinsonian syndrome had it correctly noted on death certificates. A secondary aim was to assess the accuracy of the reported cause of death.

\section{Methods}

\subsection{Study population}

Data for these analyses came from the PINE study, a prospective observational study of an incident cohort of newly diagnosed parkinsonism from 315,000 residents registered in general practices in Aberdeen, Scotland within a 4.5-year recruitment period starting in 2002. Detailed methods have been described elsewhere [8]. All consenting eligible participants had lifelong annual follow-up with a standardised assessment protocol. The specific parkinsonian diagnosis was confirmed by a single consultant neurologist with movement disorder expertise (CC) using expert clinical criteria supported by appropriate research criteria for Parkinson's disease (PD) [9], Dementia with Lewy bodies (DLB) [10], progressive supranuclear palsy (PSP) [11], multisystem atrophy (MSA) [12], corticobasal degeneration (CBD) [13] and vascular parkinsonism [14] and confirmed in some by post-mortem examination. Dementia was diagnosed prospectively by the same consultant neurologist according to clinical DSM-IV criteria, supported by annual cognitive assessments (mini-mental state examination and mini-mental parkinson's score) as part of the research protocol and by psychiatry input where required on clinical grounds.

Notification of death was performed routinely as part of follow-up and patients also gave consent for tagging to the NHS central register in order to obtain their death certificates. Patients had also given consent for their hospital and primary care (general practice) notes to be reviewed by the research team.

PINE study participants were excluded from the current analysis if they had not given consent for follow-up, were found to have a non-parkinsonian disorder on 
follow-up, were alive on 29 April 2019, were lost to follow-up, or had no available death certificate.

\subsection{Data extraction}

Demographic and clinical variables were extracted from the PINE database: sex, age at diagnosis and death, final diagnosis of the parkinsonism syndrome, place of death, and whether the patient had developed a dementia in association with their parkinsonism.

For each patient who had died, one author (HS) reviewed the available research records plus hospital records if they died in hospital and primary care records if they died at home or in a nursing home to establish the cause of death. The same author then classified the cause of death into eight categories: vascular disease including cardiac, cerebrovascular, pulmonary emboli, peripheral vascular or sudden death; cancer related; pneumonia; secondary to a fracture or fall; sepsis; renal failure/multiple organ failure; end-stage neurodegenerative disease without clear other cause; others). Deaths were then classified as being parkinsonism-related or not, namely as a result of a complication of their parkinsonism such as a fracture due to a fall, pneumonia due to aspiration or limited mobility or as a result of end stage parkinsonism or dementia e.g. if they were bed bound. Difficult cases were discussed with the other author (CC).

All death certificates followed the ICD-10 system with the following information: section I(a): disease causing death directly; I(b): other illness, leading to I(a); I(c): other illness, leading to I(b); II: other significant conditions contributing to death but not leading to the death directly [3]. One author (HS) extracted the following information from the free text on each death certificate and confirmed it with the second author: whether any parkinsonian diagnosis was recorded either as a cause of death (in section I of the death certificate) or as a contributory factor to death (in section II of the death certificate); whether it was the correct specific parkinsonian disorder compared to the final clinical diagnosis; whether a dementia diagnosis was recorded and if so what 
dementia diagnosis was given. The cause of death on part I of the death certificate also classified using the same eight group classification as used for the patient record.

\subsection{Statistical Analysis}

The sensitivity of death certificates to identify parkinsonian patients, subdivided by specific diagnosis, was calculated (i.e. [number identified by death certificate]/[total number included in cohort]) for: (1) any parkinsonian diagnosis in part I or II of the death certificate; (2) the correct specific parkinsonian diagnosis in part I or part II of the death certificate. Analyses were repeated for patients who were defined as having a parkinsonism-related death to assess whether this increased sensitivity and whether the sensitivity was affected by place of death (hospital vs community), sex, age at death (categorised as $<80,80-85$ or over 85 ) and duration of disease from diagnosis to death (categorised as $\leq 3$ years, 3-6 years, > 6 years). Differences between these groups were compared by Chi-squared statistics. In those who had dementia at death, the sensitivity of death certificates to detect this was calculated (i.e. [number with dementia mentioned on death certificate]/[total number with dementia]) and also the positive predictive value of a death certificate record of dementia.

The proportion of patients with each category of cause of death defined by our casenote review was calculated and compared with cause of death defined from the death certificate using Cohen's Kappa statistics.

Analyses were performed using IBM SPSS Statistics version 25 and VassarStats statistical computation website for $95 \%$ confidence intervals.

\subsection{Ethics}

Patients had given consent for use of their data and ethics approval for the PINE study was given by the NHS Grampian Research Ethics Committee and the Multicentre Research Ethics Committee A for Scotland. 


\section{Results}

Death certificates were available for 277 out of the 355 parkinsonian patients recruited into the PINE follow-up study (Figure 1). Median duration of follow-up from diagnosis to death was 4.2 years (range 0.5-15.1 years). Seventy-three patients (26\%) had the diagnosis confirmed at brain post-mortem. Table 1 gives the details of these patients: it is an elderly cohort (mean age at diagnosis 76.9 [SD 8.3]) in keeping with the fact that it was a population-based incident cohort and the younger onset patients remain alive. In thirteen of 277 patients there were no hospital or primary care medical records from the time of death and so there were no details on the cause of death. Dementia was diagnosed in 172 (62.1\%).

\subsection{Sensitivity of death certificates for detecting parkinsonian patients (table 2)}

When considering all parkinsonian syndromes together, any parkinsonian diagnosis was recorded on the death certificates in $66.8 \%$ (95\% $\mathrm{Cl} 60.9-72.2 \%)$. The sensitivity of any recorded parkinsonian syndrome was highest for Parkinson's disease, PSP, MSA and DLB (70.3-73.7\%) and lowest for vascular parkinsonism (31.4\%). The sensitivity of death certificates for recording the correct specific parkinsonian disorder was significantly lower at $49.5 \%$ (95\% $\mathrm{Cl} 43.4-55 \%)$ for all causes combined, with Parkinson's disease again the highest at $68.4 \%$. When the analysis was restricted to only those defined as having died as a result of their parkinsonism (parkinsonism-related deaths), the sensitivities for any parkinsonian diagnosis $(78.2 \%)$ or the correct diagnosis $(56.4 \%)$ on the death certificate increased.

3.2 Sensitivity of death certificates by disease duration at death, place of death, sex, and age at death (supplementary tables 1 to 4 )

There was clear evidence that the sensitivity for recording of any parkinsonism and the correct parkinsonian disorder on the death certificate improved with increased duration from diagnosis to death: for any parkinsonism it was $48.5 \%, 66.2 \%$ and $85.7 \%$ at three 
years, three to six years and over six years respectively (Chi-squared 31.0, $p<0.0001$ ) (supplementary table 1). This was partly due to the fact there were more parkinsonismrelated deaths as duration of follow-up lengthened: $52.5 \%, 70.1 \%, 80.6 \%$ at three years, three to six years and over six years respectively.

One hundred and thirty-four of 277 patients (48.3\%) died in the hospital, 38 cases (13.7\%) died at home and the remaining 105 (37.9\%) died in a nursing home. It was more likely (Chi-squared 21.7, $\mathrm{p}<0.0001$ ) to find any parkinsonism documented on the death certificate for patients who died at home $(78.9 \%)$ or in a nursing home $(77.1 \%)$ than in hospital (55.2\%). The same applied to a correct diagnosis on the death certificates (supplementary table 2). There was no significant effect of sex or age at death on sensitivity (supplementary tables 3 and 4).

3.3 Accuracy of dementia recorded on the death certificates (table 3)

In those parkinsonian patients with dementia the sensitivity of death certificates to detect this was $51.2 \%$ (95\% $\mathrm{Cl} 44.0-59.4 \%)$. If dementia was documented on the death certificate it had a high positive predictive value of $94.6 \%(95 \% \mathrm{Cl} 87.5-98.0 \%)$. For Parkinson's disease alone, the sensitivity and positive predictive values were $54.2 \%$ and 97.8\% respectively. In most patients with dementia, it was recorded as Parkinson's related, Lewy body dementia or unspecified dementia on the death certificate (supplementary table 5).

3.4 Causes of death and agreement between medical record review and death certificate classification (supplementary table 6)

The commonest causes of death based on medial record review were pneumonia (30\%), end stage parkinsonism (24\%) and vascular disease (22\%), whilst from death certificates it was pneumonia (33\%), vascular disease (27\%) and end stage parkinsonism (15\%). The proportion of overall primary causes matching was $62.1 \%$, with a Kappa of $0.52(p<0.001)$, representing moderate strength of agreement. As a primary cause of death, vascular disease was regarded as achieving the highest match (75.8\%), followed by pneumonia 
(71.1\%) and cancer (66.7\%).

\section{Discussion}

This study demonstrates the poor sensitivity of using death certificates to identify people who die with parkinsonian disorders and to identify those with dementia. The sensitivity was best for well-defined specific diseases such as Parkinson's disease, PSP, MSA and DLB and worse for conditions that are less well characterized such as vascular or unspecified parkinsonism. As expected, the sensitivity was higher if only deaths directly related to the parkinsonism were included but even in this group the sensitivity ranged from $40 \%$ to $86 \%$, when it should have been $100 \%$. The sensitivity was higher in those who had longer disease durations from diagnosis to death and in those who died out of hospital. One explanation for the latter may be that deaths out of hospital were more likely to be certified by primary care physicians who have a better knowledge of the patients and their underlying medical conditions. However, the details of who completed the certificate were not available to check this.

The findings from this study are in line with prior population-based research although most of the previous studies only included people with Parkinson's disease [3, 6, 7, 15-20]. The sensitivity of death certificates for a correct diagnosis of Parkinson's disease in these studies ranged from $60 \%$ [20] to $76 \%$ [16] compared to $68.4 \%$ in the current study. A study from the UK found just $53.6 \%$ of those dying with any dementia (not just parkinsonian dementia) had it recorded on their death certificates [5], similar to our figure of $51.7 \%$.

Pneumonia was observed as the most common primary cause of death (30\%) in the current study, comparable to previous studies $[18,19,20]$. However, there was only moderate agreement in the cause of death classified from death certificates compared to case note review, with under-reporting of end-stage parkinsonism and sepsis as the cause of death on death certificates.

There are several strengths in this study including: the representativeness and 
comprehensiveness of the sample which was derived from an incident cohort followed up from diagnosis to death with relatively few exclusions (other than lack of consent) and very few losses to follow-up or missing death certificates; the inclusion of all types of parkinsonism, not just Parkinson's disease; the likely accuracy of the diagnosis of each specific parkinsonian syndrome and dementia through longitudinal application of consistent expert clinical diagnosis using all available data; the classification of the cause of death from detailed case-note review.

However, some limitations should also be noted. The cause of death was established from medical records retrospectively. Ideally, this would have been done prospectively but this is difficult to do in a large study. However, this would only affect results related to parkinsonism-related deaths and cause of death and the authors believed in most cases the records gave a clear picture of why the patient had died. In addition, most previous studies of the cause of death in parkinsonism have just used death certificate data. The diagnosis of the specific parkinsonian disorder was mainly based on a clinical diagnosis rather than post-mortem confirmation (only available in $26 \%$ ) and so there may have been some misclassification of the precise diagnosis. However, this is unavoidable in most parkinsonian research due the limited numbers of post-mortems performed. There may also have been some underestimation of the number of people with dementia as detailed neuropsychological assessment of all patients was not possible and so some people with mild early dementia may have been missed using a clinical definition. This bias would mean the sensitivity of dementia recording on death certificates was overoptimistic. Finally, there was no control group of non-parkinsonian patients to calculate positive predictive values for a parkinsonian diagnosis on the death certificate.

In conclusion, a parkinsonian diagnosis is often not recorded on death certificates in people with parkinsonism, even when the death was related to it and the correct diagnosis is recorded accurately only $50 \%$ of the time. Dementia was also under-recorded. These results indicate that caution should be used in using death certificate data to identify and study the epidemiology of parkinsonian disorders and that mortality rates based on them are likely to be significant underestimates. Efforts to improve death certification in 
parkinsonian disorders are required.

\section{Acknowledgement}

We thank the members of the PINE study team who have collected and entered the data and managed the database: Kate Taylor, Robert Caslake, Angus Macleod, David McGhee, Diane Swallow, Joanne Gordon, Clare Harris, Ann Hayman, Hazel Forbes, Valerie Angus, Alasdair Finlayson, David Dawson, Katie Wilde, David Ritchie, Artur Wozniak, Aileen Sylvester, Susan Mitchell, Pam Rebecca, Ann Christie, and Diane McCosh.

The PINE study was funded by Parkinson's UK, the Scottish Chief Scientist Office, NHS Grampian endowments, the BMA Doris Hillier award, RS Macdonald Trust, the BUPA Foundation and SPRING.

\section{Conflicts of interest}

None declared 


\section{Reference List}

[1] Williams DR, Litvan I (2013) Parkinsonian Syndromes. Continuum (Minneap Minn) 19(5 Movement Disorders): 1189-1212. https://doi.org/10.1212/01.CON.0000436152.24038.e0

[2] Macleod AD, Taylor KS, Counsell CE (2014) Mortality in Parkinson's disease: a systematic review and meta-analysis. Mov Disord 29(13): 1615-22.https://doi.org/10.1002/meds.25898

[3] Hobson P, Meara J (2018) Mortality and quality of death certificate in a cohort of patients with Parkinson's disease and matched controls in North Wales, UK at 18 years: a community-based cohort study. BMJ Open 8 (2):e018969. http:// doi.org/10.1136/bmjopen$\underline{2017-018969}$

[4] Stubendorff K, Aarsland D, Minthon L, Londos E (2012) The impact of autonomic dysfunction on survival in patients with Dementia with Lewy Bodies and Parkinson's Disease with Dementia. Plos ONE 7(10): e45451. https://doi.org/10.1371/journal.pone.0045451

[5] Perera G, Stewart R, Higginson IJ, Sleeman KE (2016) Reporting of clinically diagnosed dementia on death certificates: retrospective cohort study. Age and Ageing 45(5):66873.https://doi.org/10.1093/ageing/afw077

[6] Leon JB, Louis ED, Villarejo-Galende A, Romero JP, Bermejo-Pareja F (2014) Underreporting of Parkinson's disease on death certificates: A population-based study (NEDICES). Jourof the Neurological Sciences 347: 188-192. https://dx.doi.org/10.1016/i.jns.2014.08.048 
[7] Moscovich M, Boschetti G, Moro A, Teive HAG, Hassan A, Munhoz RP (2017) Death certificate data and causes of death in patients with parkinsonism. Parkinsonism and Related Disorders 41: 99-103. http://dx.doi.org/10.1016/i.parkreldis.2017.05.022

[8] Caslake R, Taylor K, Scott N, Gordon J, Harris C, Wilde K, Murray A, Counsell C (2013) Age-, gender-, and socioeconomic status-specific incidence of Parkinson's disease and parkinsonism in northeast Scotland: the PINE study. Parkinsonism Relat Disord 19(5):515-21. http://dx.doi.org/10.1016/i.parkreldis.2013.01.014

[9] Hughes AJ, Daniel SE, Kilford L, Lees AJ (1992) Accuracy of clinical diagnosis of idiopathic Parkinson's disease: a clinico-pathological study of 100 cases. Journal of Neurology, Neurosurgery \& Psychiatry 55(3):181-4. http://dx.doi.org/10.1136/innp.55.3.181

[10] McKeith IG, Dickson DW, Lowe J, Emre M, O'brien JT, Feldman H, Cummings J, Duda JE, Lippa C, Perry EK, Aarsland D (2005) Diagnosis and management of dementia with Lewy bodies third report of the DLB consortium. Neurology 65(12):1863 -

72. https://doi.org/10.1212/01.wnl.0000187889.17253.b1

[11] Litvan I, Agid Y, Calne D, Campbell G, Dubois B, Duvoisin RC, Goetz CG, Golbe LI, Grafman J, Growdon JH, Hallett M (1996) Clinical research criteria for the diagnosis of progressive supranuclear palsy (Steele-Richardson-Olszewski syndrome) report of the NINDS-SPSP international workshop. Neurology 47(1):1-9.

https://doi.org/10.1212/WNL.47.1.1

[12] Gilman S, Wenning GK, Low PA, Brooks DJ, Mathias CJ, Trojanowski JQ, Wood NW, Colosimo C, Dürr A, Fowler CJ, Kaufmann H (2008) Second consensus statement on the diagnosis of multiple system atrophy. Neurology 71(9):670-

6. https://doi.org/10.1212/01.wnl.0000324625.00404.15 
[13] Bak TH, Hodges JR (2008) Corticobasal degeneration: clinical aspects. Handbook of clinical neurology 89:509-21. https:// doi.org/10.1016/S0072-9752(07)01247-X.

[14] Zijlmans JC, Daniel SE, Hughes AJ, Révész T, Lees AJ (2004) Clinicopathological investigation of vascular parkinsonism, including clinical criteria for diagnosis. Movement disorders: official journal of the Movement Disorder Society 19(6):630-

40. https://doi.org/10.1002/mds.20083

[15] Wermuth L, Stenager EN, Stenager E, Boldsen J (1995) Mortality in patients with Parkinson's disease. Acta Neurol Scand 92(1):55-8.

http://www.ncbi.nim.nih.gov/pubmed/7572061

[16] Philips NJ, Reay J, Martyn CN (1999) Validity of mortality data for Parkinson's disease. J Epidemiol Community Health 53(9): 587-588. http://doi.org/10.1136/jech.53.9.587

[17] Pressley JC, Tang MX, Marder K, Cote LJ, Mayeux R (2005) Disparities in the recording of Parkinson's disease on death certificates. Mov Disord 20(3): 315-321.

https://www.ncbi.nIm.noh.gov/pubmed/15580618

[18] Feldman AL, Johansson ALV, Gatz M, Flensburg M, Petzinger GM, Widner H, Lew MF, Pedersen NL, Wirdefeldt K (2012) Accuracy and sensitivity of parkinsonian disorder diagnoses in two Swedish National Health Registers. Neuroepidemiology 38: 186-193. https://doi.org/10.1159/000336356

[19] Nath U, Thomson R, Wood R, Ben-Shlomo Y, Lees A, Rooney C, Burn D (2005) Population based mortality and quality of death certification in progressive supranuclear palsy (Steele-Richardson-Olszewski syndrome). J Neurol Neurosurg Psychiatry 76(4): 498502. http://doi.org/10.1136/jnnp.2004.039370 
[20] Williams-Gray CH, Mason SL, Evans JR, Foltynie T, Brayne C, Robbins TW, Barker RA (2013) The CamPalGN study of Parkinson's disease: 10-year outlook in an accident population-based cohort. JNNP 0:1-7. http:// doi:10.1136/innp-2013-305277 
Table 1: Baseline demographic and clinical characteristic of patients with Parkinsonism

\begin{tabular}{|c|c|c|}
\hline $\begin{array}{c}\text { Characteristics at baseline } \\
\text { assessment }\end{array}$ & \multicolumn{2}{|c|}{$\begin{array}{l}\text { Patients with Parkinsonism } \\
\qquad(\mathrm{N}=277)\end{array}$} \\
\hline Mean age baseline (years, [SD*]) & \multicolumn{2}{|c|}{$76.9(8.3)$} \\
\hline Mean age at death (years, [SD*]) & \multicolumn{2}{|c|}{$81.9(8.0)$} \\
\hline Male & \multicolumn{2}{|c|}{$180(65.0 \%)$} \\
\hline Specific Parkinsonian Diagnosis & Total Number & $\begin{array}{l}\text { Number with } \\
\text { dementia }\end{array}$ \\
\hline Idiopathic Parkinson's Disease & $152(54.9 \%)$ & $81(53.3 \%)$ \\
\hline Dementia with Lewy Bodies & $37(13.4 \%)$ & $37(100 \%)$ \\
\hline Vascular Parkinsonism & $35(12.6 \%)$ & $24(68.6 \%)$ \\
\hline Progressive Supranuclear Palsy & $30(10.8 \%)$ & $17(56.7 \%)$ \\
\hline Multiple System Atrophy & $11(4.0 \%)$ & $3(27.3 \%)$ \\
\hline $\begin{array}{l}\text { Dementia with Associated } \\
\text { Parkinsonism }\end{array}$ & $7(2.5 \%)$ & 7 (100\%) \\
\hline Parkinsonism (Unspecified) & $3(1.1 \%)$ & $1(33.3 \%)$ \\
\hline Corticobasal Degeneration & $2(0.7 \%)$ & $2(100 \%)$ \\
\hline \multirow{3}{*}{ Place of Death } & Hospital & $134(48.3 \%)$ \\
\hline & Home & $38(13.7 \%)$ \\
\hline & Nursing Home & 105 (37.9\%) \\
\hline
\end{tabular}

SD*: Standard deviation 
Table 2: Frequency of any and correct parkinsonian diagnosis on death certificates for all parkinsonian cases and those with parkinsonian related death

\begin{tabular}{|c|c|c|c|c|}
\hline \multirow{3}{*}{ Types of Parkinsonism } & \multicolumn{4}{|c|}{ Sensitivity (95\% Cl* (\%)) } \\
\hline & \multicolumn{2}{|c|}{$\begin{array}{l}\text { Any parkinsonism on death } \\
\text { certificate }\end{array}$} & \multicolumn{2}{|c|}{$\begin{array}{l}\text { Correct parkinsonian diagnosis on } \\
\text { death certificate }\end{array}$} \\
\hline & All & $\begin{array}{l}\text { Park related } \\
\text { death }\end{array}$ & All & $\begin{array}{l}\text { Park related } \\
\text { death }\end{array}$ \\
\hline Idiopathic Parkinson's Disease & $\begin{array}{c}112 / 152=73.7 \% \\
(65.8-80.3)\end{array}$ & $\begin{array}{c}83 / 97=85.6 \% \\
(76.6-91.6)\end{array}$ & $\begin{array}{c}104 / 152=68.4 \% \\
(60.3-75.6)\end{array}$ & $\begin{array}{c}75 / 97=77.3 \% \\
(67.5-85.0)\end{array}$ \\
\hline Progressive Supranuclear Palsy & $\begin{array}{c}22 / 30=73.3 \% \\
(53.8-87.0)\end{array}$ & $\begin{array}{c}20 / 26=76.9 \% \\
(55.9-90.2)\end{array}$ & $\begin{array}{c}12 / 30=40.0 \% \\
(23.2-59.2)\end{array}$ & $\begin{array}{c}11 / 26=42.3 \% \\
(24.0-62.8)\end{array}$ \\
\hline Multiple System Atrophy & $\begin{array}{c}8 / 11=72.7 \% \\
(39.3-92.7)\end{array}$ & $\begin{array}{l}6 / 7=85.7 \% \\
(42.0-99.2)\end{array}$ & $\begin{array}{c}2 / 11=18.2 \% \\
(3.2-52.2)\end{array}$ & $\begin{array}{c}2 / 7=28.6 \% \\
(5.1-69.7)\end{array}$ \\
\hline Corticobasal Degeneration & $\begin{array}{c}1 / 2=50.0 \% \\
(2.7-97.3)\end{array}$ & $\begin{array}{l}1 / 2=50.0 \% \\
(2.7-97.3)\end{array}$ & $\begin{array}{l}1 / 2=50.0 \% \\
(2.7-97.3)\end{array}$ & $\begin{array}{c}1 / 2=50.0 \% \\
(2.7-97.3)\end{array}$ \\
\hline Vascular Parkinsonism & $\begin{array}{c}11 / 35=31.4 \% \\
(17.4-49.4)\end{array}$ & $\begin{array}{c}6 / 15=40.0 \% \\
(17.5-67.1)\end{array}$ & $\begin{array}{c}3 / 35=8.6 \% \\
(2.2-24.2)\end{array}$ & $\begin{array}{c}2 / 15=13.3 \% \\
(2.3-41.6)\end{array}$ \\
\hline Dementia with Lewy Bodies & $\begin{array}{c}26 / 37=70.3 \% \\
(52.8-83.6)\end{array}$ & $\begin{array}{c}26 / 34=76.5 \% \\
(58.4-88.6)\end{array}$ & $\begin{array}{c}15 / 37=40.5 \% \\
(25.2-57.8)\end{array}$ & $\begin{array}{c}15 / 34=44.1 \% \\
(27.6-61.9)\end{array}$ \\
\hline Parkinsonism (Unspecified) & $\begin{array}{c}1 / 3=33.3 \% \\
(1.8-87.5)\end{array}$ & $\begin{array}{c}1 / 2=50.0 \% \\
(2.7-97.3)\end{array}$ & $\begin{array}{l}0 / 3=0.0 \% \\
(0.0-69.0)\end{array}$ & $\begin{array}{l}0 / 2=0.0 \% \\
(0.0-80.2)\end{array}$ \\
\hline $\begin{array}{c}\text { Dementia with Associated } \\
\text { Parkinsonism }\end{array}$ & $\begin{array}{l}4 / 7=57.1 \% \\
(20.2-88.2)\end{array}$ & $\begin{array}{l}4 / 5=80.0 \% \\
(30.0-99.0)\end{array}$ & $\begin{array}{l}0 / 7=0.0 \% \\
(0.0-44.0) \\
\end{array}$ & $\begin{array}{l}0 / 5=0.0 \% \\
(0.0-53.7)\end{array}$ \\
\hline All Parkinsonian Disorders & $\begin{array}{c}185 / 277=66.8 \% \\
(60.9-72.2)\end{array}$ & $\begin{array}{c}147 / 188=78.2 \% \\
(71.5-83.7)\end{array}$ & $\begin{array}{c}137 / 277=49.5 \% \\
(43.4-55.5)\end{array}$ & $\begin{array}{c}106 / 188=56.4 \% \\
(49.0-63.5)\end{array}$ \\
\hline
\end{tabular}

$\mathrm{Cl}^{*}$ : confidence interval 
Table 3: Presence of Dementia diagnoses on death certificates

Clinical Dementia Diagnosis

Dementia on

Death Certificates

\begin{tabular}{|l|c|c|l|}
\cline { 2 - 3 } \multicolumn{1}{c|}{} & YES & NO & \multicolumn{1}{c}{} \\
\hline YES & $88(51.2 \%)$ & $5(4.7 \%)$ & 93 \\
\hline NO & $84(48.8 \%)$ & $100(95.3 \%)$ & 184 \\
\cline { 2 - 4 } & 172 & 107 & 277 \\
\hline
\end{tabular}


Supplementary table 1: Frequency of any parkinsonism / correct parkinsonian diagnosis on death certificate (DC) by duration of disease

\begin{tabular}{|c|c|c|}
\hline \multirow{2}{*}{$\begin{array}{l}\text { Disease duration } \\
\text { (yrs) }\end{array}$} & \multicolumn{2}{|c|}{ Sensitivity } \\
\cline { 2 - 3 } & $\begin{array}{l}\text { Parkinsonism on } \\
\text { DCs }\end{array}$ & $\begin{array}{l}\text { Correct } \\
\text { parkinsonian } \\
\text { diagnosis on DC }\end{array}$ \\
\hline$\leq 3.0$ & $49 / 101(48.5 \%)$ & $29 / 101(28.7 \%)$ \\
\hline $3.01-6.0$ & $51 / 77(66.2 \%)$ & $41 / 77(53.2 \%)$ \\
\hline$\geq 6.01$ & $84 / 98(85.7 \%)$ & $74 / 98(75.5 \%)$ \\
\hline
\end{tabular}

Supplementary table 2: Frequency of any parkinsonism / correct parkinsonian diagnosis on death certificates (DC) in different places of death

\begin{tabular}{|c|c|c|}
\hline \multirow{2}{*}{ Place of Death } & \multicolumn{2}{|c|}{ Sensitivity } \\
\cline { 2 - 3 } & $\begin{array}{l}\text { Parkinsonism on } \\
\text { DCs }\end{array}$ & $\begin{array}{l}\text { Correct } \\
\text { parkinsonian } \\
\text { diagnosis on DC }\end{array}$ \\
\hline Hospital & $74 / 134(55.2 \%)$ & $59 / 134(44.0 \%)$ \\
\hline Home & $30 / 38(78.9 \%)$ & $24 / 38(63.2 \%$ \\
\hline Nursing Home & $81 / 105(77.1 \%)$ & $61 / 105(58.1 \%)$ \\
\hline
\end{tabular}

Supplementary table 3: Frequency of any parkinsonism / correct parkinsonian diagnosis on death certificate (DC) by sex

\begin{tabular}{|c|c|c|}
\hline \multirow{2}{*}{} & \multicolumn{2}{|c|}{ Sensitivity } \\
\cline { 2 - 3 } & $\begin{array}{l}\text { Parkinsonism on } \\
\text { DCs }\end{array}$ & $\begin{array}{l}\text { Correct } \\
\text { parkinsonian } \\
\text { diagnosis on DC }\end{array}$ \\
\hline Male & $127 / 180(70.6 \%)$ & $96 / 180(53.3 \%)$ \\
\hline Female & $58 / 97(59.8 \%)$ & $49 / 97(50.5 \%)$ \\
\hline
\end{tabular}

Supplementary table 4: Frequency of any parkinsonism / correct parkinsonian diagnosis on death certificate (DC) by age at death

\begin{tabular}{|c|l|l|}
\hline \multirow{2}{*}{ Age at death (yrs) } & \multicolumn{2}{|c|}{ Sensitivity } \\
\cline { 2 - 3 } & $\begin{array}{l}\text { Parkinsonism on } \\
\text { DCs }\end{array}$ & $\begin{array}{l}\text { Correct } \\
\text { parkinsonian } \\
\text { diagnosis on DC }\end{array}$ \\
\hline$\leq 80.0$ & $59 / 88(67.0 \%)$ & $46 / 88(52.3 \%)$ \\
\hline $80.01-85.0$ & $58 / 85(68.2 \%)$ & $47 / 85(55.3 \%)$ \\
\hline$\geq 85.0$ & $68 / 104(66.8 \%)$ & $52 / 104(50.0 \%)$ \\
\hline
\end{tabular}


Supplementary table 5: Number and percentage of cases with various dementia recorded on death certificates

\begin{tabular}{|c|c|}
\hline Types of Dementia & $\begin{array}{c}\text { Cases Number and Percentage } \\
\mathrm{N}(\%)\end{array}$ \\
\hline $\begin{array}{c}\text { Parkinson's disease dementia/ Dementia with } \\
\text { Lewy Bodies }\end{array}$ & $33(37.1)$ \\
\hline Other Dementia & $3(3.3)$ \\
\hline Alzheimer's Disease & $9(10.1)$ \\
\hline Dementia (Unspecified) & $36(40.5)$ \\
\hline Vascular Dementia & $5(5.7)$ \\
\hline Mixed Dementia & $3(3.3)$ \\
\hline Total & $89(100)$ \\
\hline
\end{tabular}

Supplementary table 6: Primary causes of death for parkinsonian cases

\begin{tabular}{|c|c|c|c|}
\hline Causes of death & $\begin{array}{c}\text { Confirmed from } \\
\text { medical records } \\
\mathrm{N}(\%)\end{array}$ & $\begin{array}{c}\text { Recorded on } \\
\text { death certificate } \\
\mathrm{N}(\%)\end{array}$ & $\begin{array}{c}\text { Cases with } \\
\text { agreement between } \\
\text { medical records and } \\
\text { death certificate } \\
\mathrm{N}(\%)\end{array}$ \\
\hline Pneumonia & $83(30.0)$ & $92(33.2)$ & $59(71.1)$ \\
\hline $\begin{array}{c}\text { End-stage } \\
\text { neurodegenerative disease }\end{array}$ & $67(24.2)$ & $43(15.5)$ & $33(49.3)$ \\
\hline Vascular Disease & $62(22.4)$ & $74(26.7)$ & $47(75.8)$ \\
\hline Sepsis & $28(10.1)$ & $14(5.1)$ & $11(39.3)$ \\
\hline Cancer & $12(4.3)$ & $10(3.6)$ & $8(66.7)$ \\
\hline $\begin{array}{c}\text { Renal failure/Multiple } \\
\text { organ failure }\end{array}$ & $10(3.6)$ & $9(3.2)$ & $5(50.0)$ \\
\hline Fracture or Fall & $1(0.4)$ & $2(0.7)$ & $0(0.0)$ \\
\hline Other Disease/ Unknown & $1(5.0)$ & $33(11.9)$ & $1(100.0)$ \\
\hline Total & $264(100.0)$ & $277(100.0)$ & $164(62.1)$ \\
\hline
\end{tabular}

*Other disease includes COPD, peritonitis, pleural effusion, gastroenteritis, UTI, Fibrosing alveolitis, perforated duodenal ulcer, fragility, acute bowel obstruction, pancreatitis, gastrointestinal bleed, choking, Crohn's disease. Unknown means missing GPs' notes. 